\title{
Estágios Básicos: como as práticas profissionais e as Diretrizes Curriculares Nacionais repercutem na formação e atuação do psicólogo
}

\author{
Basic Internships: How the professional practices and the National Curriculum Guidelines affect \\ the education and performance of psychologists
}

Carla Fabiane Worciekowski[a], Adolfo Pizzinato ${ }^{[b]}$

\footnotetext{
${ }^{[a]}$ Mestre em Psicologia Social pela PUC-RS, professora horista do Centro Universitário Metodista IPA, tutora de projeto desenvolvido pelo Programa de Educação em Trabalho, Porto Alegre, RS - Brasil, e-mail: fabi woy@yahoo.com.br.

${ }^{[b]}$ [b] Doutor em Psicologia da Educação pela Universitat Autònoma de Barcelona, professor da Faculdade de Psicologia da PUC-RS, coordenador do grupo de pesquisa "Identidades, narrativas e comunidades de prática", Barcelona, Catalunha - Espanha, e-mail: Adolfo.pizzinato@pucrs. br.
}

Recebido: $19 / 08 / 2013$ Received: 08/19/2013

Aprovado: 04/11/2013 Approved: 11/04/2013

\section{Resumo}

Atualmente, a perspectiva de educação continuada pressupõe uma formação profissional permanente em sintonia com as "práticas" profissionais. Este artigo discute o reflexo das modificações propostas com a abertura das Diretrizes Curriculares Nacionais (DNC) na formação do psicólogo brasileiro, mediante projetos pedagógicos que enfatizam a formação generalista a partir de uma experiência na formação. Ao propor a capacidade crítica dos fenômenos socioculturais inseridos em diferentes campos de atuação profissional que ampliem as possibilidades de circulação e construção de saberes e práticas do psicólogo, investigam-se os desdobramentos destas diretrizes ao desenvolver práticas psicológicas em contextos de atuação coletiva para além dos já tradicionais. Partindo da experiência de supervisão em um curso de Psicologia em implantação, pesquisa-se quais desafios e alternativas se apresentam e são ofertadas, e a inserção dos estudantes em estágios básicos de formação, antecipando a prática e entendendo que esta modalidade faz-se necessária diante das novas demandas da profissão, muitas vezes entrincheirada entre o tradicional e o ampliado.

Palavras-chave: Formação de psicólogos. Formação profissional. Estágios em Psicologia.

\begin{abstract}
Currently, the perspective of continuing education presupposes a permanent vocational training in line with the professional "practices". This article discusses the impact of the proposed changes with the opening of the National Curriculum Guidelines (DNC) on the formation of the Brazilian psychologist, through educational projects that emphasize general education from an experience in the formation. In proposing the critical capacity of sociocultural phenomena inserted in different fields of professional activity that broaden the potential circulation and construction of knowledge and practices of the psychologist, we investigate the consequences of these guidelines to develop psychological practices in contexts of collective action beyond the traditional ones. From
\end{abstract}

Psicol. Argum. 2014, 32(79), Supl. 2, 45-56 
the supervisory experience in a Psychology course in deployment, we search which challenges and alternatives are presented and offered, and the inclusion of students in Basic Internships for training, anticipating the practice and understanding that this modality is necessary due to the new demands of the profession, often entrenched between traditional and expanded.

Keywords: Training of Psychologists. Vocational training. Internships in Psychology.

\section{Introdução}

As considerações aqui apresentadas partem do lugar de docente e de minha experiência na supervisão dos Estágios Básicos (EBs) em um curso de Psicologia da cidade que obteve seu reconhecimento em 2011. Propõe-se com este estudo investigar e compreender a posição das práticas psicológicas a partir das vivências promovidas por este curso de graduação na interlocução com a Política de Educação Superior e as Diretrizes Curriculares Nacionais (DCN) da área. Problematiza-se e discute-se as experiências e desafios dos estudantes que realizam seus EBs nos campos acessados relacionando estas práticas com as ênfases propostas pelo referido curso. Pesquisando sobre os efeitos produzidos no campo das práticas dos profissionais em formação, emerge uma questão: como se dá a aproximação entre os saberes teórico-práticos diante de diversas realidades das práticas profissionais? 0 que acrescentaria para a Psicologia uma formação profissional ininterrupta que se pressupõe em contato direto com as práticas profissionais?

Nesse sentido, organizou-se uma pesquisa com o objetivo de investigar como se dá a inserção e a atuação dos estudantes em Estágio Básico nos diversificados espaços de práticas ofertados (clínicas e instituições tradicionais de formação, serviços públicos de saúde/assistência e o terceiro setor), perante uma formação profissional que pretende ampliar o ensino para além dos modelos tradicionais da clínica e o que isso significa. Tendo por meta uma formação que contemple a execução de intervenções psicossociais em diferentes contextos como, por exemplo, na atenção integral à saúde, pesquisaram-se quais são os percalços/limites e as alternativas ofertadas na formação dita mais ampliada em um curso novo que se apresenta com uma missão formativa para além das práticas tradicionais já conhecidas (médicas curativas, individuais, assistencialistas e especializadas). Este artigo também objetiva refletir sobre sua relação com a formação do psicólogo diante das novas demandas e exigências de atuação na atualidade pautadas no discurso do compromisso/responsabilidade social, identificando as competências e habilidades necessárias hoje na proposta sugerida pelas DCN, enquanto formação e aperfeiçoamento permanentes de conhecimento.

Antes das DCN, a maioria dos cursos de Psicologia se organizava nos três estágios tradicionais obrigatórios (Psicologia clínica, escolar e do trabalho), enquanto áreas de conhecimento hegemônicas eram associadas ao campo de atuação, sustentando determinados exercícios profissionais em Psicologia (J. Bernardes, 2006; Yamamoto, 2003; Yamamoto \& Oliveira, 2010; Ribeiro \& Luizio, 2008). Com as modificações propostas, não ocorrem mais por especialidades, sendo condensados a dois estágios/ ênfases, em temáticas ofertadas aos estudantes, evitando a exclusão entre as escolhas realizadas. Neste formato, almejam oportunizar uma formação que rompa com a "racionalidade prática" e, portanto, atente para as questões da vida, na busca de transformações sociais e atendendo as necessidades populacionais.

Levando-se em conta que a formação em Psicologia tem sido duplamente especializada e estabelecida, uma vez que é individualizante e intimista, propor uma formação generalista não se reduz a um transitar entre áreas ou campos de atuação em Psicologia em curto espaço, e também não se resume à agregação da experiência dos estudantes por meio de uma mistura de diferentes áreas/campos de atuação, confundindo-se com pluralidade ou diversidade. Atenta-se para o fato de que as ditas habilidades (no corpo/psiquismo do indivíduo) e competências (objetivos/definição de operações cognitivas/indivíduo-centrado), herdeiras de matérias e disciplinas do currículo mínimo surgem com o conceito de perfil formativo (edital no 4/1997 do Ministério da Educação) e centram 
mais uma vez nos perfis individuais, reportando a desempenho e atuação requeridos do formando. A crítica ressignifica os conceitos avançando nos processos das reformas curriculares e ultrapassa uma visão utilitarista e instrumental do currículo, reduzida às perspectivas individualistas ou cognitivistas, preocupada com objetivos e metas, limitando as potencialidades humanas ao deixar de problematizar o conhecimento e a cultura como campos plurais de conflitos e acordos (J. Bernardes, 2012; Yamamoto \& Oliveira, 2010).

A inclusão do psicólogo na saúde pública coincide com as muitas críticas ao trabalho clínico tradicional, destinado a uma minoria, com forte conteúdo ideológico individualista e falta de respostas satisfatórias às questões sociais. Na busca de uma função socialmente reconhecida, aliada ao declínio social da categoria na década de 1980 , com a recessão da classe média, grande consumidora das práticas psicológicas, os profissionais são impulsionados para novas formas de inserção incentivadas pelo CFP, com investimentos na construção de uma identidade profissional atrelada à saúde ampliada e ao diálogo da Psicologia como espaço de referência com a sociedade, configurando um mercado estável para a área (Conselho Federal de Psicologia [CFP], 2006; J. Bernardes, 2012; Dimenstein \& Macedo, 2012). Assim, se constrói um novo lugar social e se inventa um operador que legitima a categoria, ampliando sua presença no campo das políticas públicas e práticas sociais na disputa por espaço no mercado de trabalho e investimentos estratégicos e na abertura de novos cursos, programas e serviços ligados a políticas públicas (saúde, saúde mental, assistência social e instalação da rede de proteção de direitos).

A partir disto, definem-se tecnologias na atuação e intervenção na resolução de problemas, na correção dos desajustes e desvios identificados nas engrenagens sociais: "a Psicologia oferece para a saúde pública a interioridade do sujeito público e a racionalidade técnica para seu governo." (A. G. Bernardes, 2010, p. 214).

A atuação protegida do psicólogo como profissional liberal/autônomo, consequência da ênfase desse modelo na graduação, tem dificultado a construção de novos processos de trabalho que se impuseram com o aumento da participação da categoria nos serviços públicos de saúde e nos vários níveis de assistência à saúde. Aceitar a condição de trabalhar no SUS significa um progressivo distanciamento daquele modelo vigente para uma atuação que responda à relação entre a questão social e as políticas (Yamamoto, 2003). 0 fato é que os psicólogos inseridos em equipes multiprofissionais têm desenvolvido uma quantidade maior e mais diversa de atividades, tendência que tem exigido mais habilidades e competências (Lima \& Santos, 2012).

Discute-se um formato proposto em que as competências e habilidades vão sendo construídas gradativamente, em uma progressiva inserção do estudante nos campos de estágio encorajados a analisar as demandas e sua implicação com a tarefa. Como recorte, optou-se pelos EBs justamente por consistirem em práticas inseridas em um conjunto de atividades que compõem uma prática profissional e buscam antecipá-la no curso, sinalizando a importância de que prática e teoria não sejam vistas como momentos estanques na estrutura curricular (Associação Brasileira de Ensino e Pesquisa [ABEP], 2009). A tentativa é romper com o modelo tradicional de estrutura curricular que concentrava toda a prática no final do curso e transformava os estágios finais no efetivo momento de aquisição de competências profissionais.

Entende-se aqui que as práticas de estágio investigadas (EBs) constroem a realidade da formação atual, partindo de uma construção conjunta e interativa entre pessoas e ambientes. Desta forma, a construção do corpus de dados priorizou ferramentas como a observação participante da pesquisadora e a elaboração e posterior reflexão dos diários de campo realizados tanto pela pesquisadora quanto pelos participantes do estudo (estudantes acessados em supervisão dos Estágios básicos). Na pretensão de identificar o que esses campos têm exigido dos estudantes em termos de saberes, práticas e disposição para neles atuar, considera-se aqui como os profissionais/supervisores locais se desempenham e se relacionam com os contextos em que estão imersos. Ao investigar como os estudantes dialogam no espaço de formação acadêmica que se propõe interdisciplinar, no caso analisado, a supervisão acadêmica torna-se relevante dispositivo de significação, que aliada ao registro sistemático em forma do diário instiga a produção do exercício reflexivo e a análise da implicação pelos estudantes. Nesse sentido, os diários de campo dos estudantes são apresentados no intuito de "ilustrar" situações de tensão, onde parece de fato ocorrer algum

Psicol. Argum. 2014, 32(79), Supl. 2, 45-56 
movimento de aprendizagem significativamente divergente do mero ensino reprodutivista da técnica.

\section{Método}

Esta pesquisa partiu da observação participante nos grupos de supervisão acadêmica (como supervisora referência), aliada à discussão das vivências nos Estágios Básicos (II - observação; III - elaboração de proposta de intervenção; IV - intervenção posta em prática) registradas nos diários de campo elaborados por estudantes do curso de Psicologia de um Centro Universitário da cidade de Porto Alegre em seus respectivos EBs. Após aprovação dos Comitês de Ética em Pesquisa da PUCRS e do Centro Universitário pesquisado (CAAE: 01599812.0.0000.5336), buscaram-se os alunos para discutir suas vivências com os psicólogos supervisores locais/representantes de locais já credenciados e que se dispunham a apresentar seus diários de campo de estágio. Os diários foram analisados a partir do aceite dos participantes, disponibilizando estes no final dos semestres 2011-02 e 2012-01, após a entrega das avaliações para que não houvesse nenhuma vinculação entre a avaliação/nota dada pela supervisora acadêmica-pesquisadora e a pesquisa em questão, visto que os diários já são produzidos como parte da tarefa acadêmica nestes grupos. Soma-se a isso o convite a cada participante estudante, acessado em grupos de supervisão acadêmica no final do semestre após a entrega das avaliações e notas. Havendo o aceite, foi solicitada a autorização para pesquisa nos diários de campo já elaborados, explicitando os objetivos da pesquisa e os procedimentos éticos e metodológicos realizados para o estudo.

O corpus inclui ainda os diários de campo elaborados pela própria pesquisadora nos espaços de supervisão acadêmica, no mesmo período, além da análise de fontes secundárias de informação (documentos provenientes das DCN, ABEP, CFP e o PPC do curso em questão).

No caso descrito, a implantação dos EBs ocorre pela articulação dos estudantes em grupos que se revezam a cada semestre nos diferentes campos de estágio ofertados pelo Serviço Escola de Psicologia do Centro Universitário eleito. Os EBs iniciam no segundo semestre do curso e são concluídos no sexto, oportunizando experiências reais de inserção dos estudantes em espaços de prática profissional do psicólogo. Há uma tentativa de privilegiar campos que articulem competências e habilidades ligadas as ênfases do curso:
Saúde Coletiva e Direitos Humanos, em que os estudantes permanecem pelo menos duas horas semanais no campo de estágio, acompanhados por um psicólogo do serviço concedente, com um plano de atividades correspondente às suas condições atuais, gerenciado pelo Centro Universitário e pelo Serviço. Somam-se a este duas horas semanais de supervisão acadêmica no Centro Universitário, nas quais os estudantes são acolhidos em um grupo de no máximo dez alunos por um supervisor/professor que acompanha o desenvolvimento das atividades e a produção de um diário de campo como forma de registro e problematização. É um formato que objetiva construir projetos em parceria com os campos de estágio, diminuindo a relação utilitarista nas atividades de observação tradicionais e rompendo com o modelo que tenta isolar o objeto para permitir a ação do observador.

$\mathrm{Na}$ observação participante oportuniza-se unir o objeto a seu contexto, contrapondo-se ao princípio de isolamento no qual fomos formados. Ao integrar o observador à sua observação e o conhecedor ao seu conhecimento, a observação participante inclui sujeitos sociais, fundamentais no processo de investigação, resultado dos movimentos dos corpos humanos nas diversas vertentes de sua interação. A partir daí, considera-se a construção do corpus de conhecimento do objeto de estudo que é sempre carregado de incerteza (Queiroz, Vall, Souza \& Vieira, 2007, p. 278).

Para a análise qualitativa dos dados foi utilizada a estratégia metodológica baseada na tradição da Análise do Discurso (Fairclough, 2001; Iñiguez, 2005; Maingueneau, 2010), que permite não apenas a análise do que está explícito nos textos, mas também do que está implícito. A ênfase nesta pesquisa se deu na investigação de uma formação dita mais emergente representada por um curso de Psicologia recentemente reconhecido pelo MEC, na tentativa de ampliar a formação para além dos modelos e as práticas consideradas mais tradicionais. Investiga-se qual a repercussão na formação dos estudantes deste curso, entendendo que esta perspectiva busca contribuir para dar visibilidade a discursos que operam em diferentes planos, no sentido de compreender o que ocorre quando se pretende avançar com um modelo de formação. Por meio da análise dos fragmentos discursivos, práticas e enunciados de estudantes e da própria autora (além dos institucionais), problematiza-se os mecanismos mantenedores da reprodução, normatização e cristalização das práticas já estabelecidas. Concomitantemente, são provocados e convocados a 
inventar, criar, experimentar, conhecer, ousar saberes e fazeres apresentando novas possibilidades de aprendizagem e atuação. Nesta empreitada indaga-se o que se pode gerar, movimentar na formação em Psicologia para além das formas já hegemônicas na atual formação proposta pelas DCN.

A partir da perspectiva metodológica da Análise do Discurso, Maingueneau (2010) ressalta que a análise do discurso é de toda maneira crítica pelo simples fato de que não autonomiza os textos, mas os relaciona a práticas sociais e a interesses situados, e também afirma que toda análise do discurso implica em uma perda de controle por parte dos sujeitos, ao colocar em questão a própria categoria de Sujeito, que se encontra dispersa em uma pluralidade de práticas discursivas reguladas e dominadas por um interdiscurso. Assim, parte-se da ideia de que todo discurso existe em relação a uma prática social e assume-se que o discurso não só está determinado pelas instituições e as estruturas sociais, mas que é parte constitutiva delas (Iñiguez, 2005, p. 94). Nesse sentido, Fairclough (2001) alerta-nos que o que é específico de uma prática discursiva particular depende da prática social, da qual é uma faceta, no caso descrito, enquanto prática ainda em processo de consolidação institucional, em construção. Partindo de uma amostra discursiva particular ao considerar o contexto interdiscursivo, um conjunto de questões começa a atuar como indicadores havendo uma constante alternância nos tipos de discurso delineados e configurados na orientação prevista (Fairclough, 2001, p. 282).

O corpus construído para este estudo partiu do registro de material coletado dos diários de campo (20 estudantes ao todo) em supervisão nos grupos de Estágio Básico (12 EBII, 5 EBIII e 3 EBIV), sendo ampliado por meio da inclusão do registro da autora principal em seu próprio diário de campo. Os registros foram discutidos em supervisão acadêmica entre os semestres 2011-02 e 2012-01, perfazendo uma média de 16 encontros para cada grupo, totalizando 64 encontros ao todo para a discussão de todos os diários produzidos no período. No processo de análise, os diários foram agrupados em uma grande categoria discursiva, a partir de uma definição dos principais marcadores $a$ priori, orientados pelos objetivos da pesquisa. A categoria central do estudo foi denominada "construção de práticas", caracterizada, centralmente, pelo marcador "aprender fazendo", que diz respeito às práticas tradicionais e à emergência de novas atuações e fazeres na perspectiva das ênfases propostas.

\section{Resultados e Discussão}

Partindo da primeira categoria teórica de análise, ou seja, "mapeamento e a caracterização dos espaços/locais de estágio e suas respectivas práticas", representada nos grupos de supervisão acadêmica do centro universitário estudado, foram elencados três grupos que englobaram dez locais ao todo: 1. institutos e clínicas tradicionais de formação, incluindo aqui o Serviço Escola de Psicologia (4 locais); 2. serviços públicos (4 locais); 3. terceiro setor - organizações não governamentais, entidades comunitárias e fundações - (2 locais).

Um ponto importante a ser considerado é que na composição das categorias a priori (teóricas) dos relatos nos diários esperava-se que a oferta de práticas "tradicionais" somente fosse confirmada no primeiro grupo, o que acabou se comprovando a partir das atividades descritas, desde a observação das reuniões clínicas/triagens e do centro de estudantes até a participação em atividade de tutoria e como ouvinte na apresentação de seminários científicos e de trabalhos, estudos de caso de psicopatologia (locais 1 e 2), porém não se restringindo a este grupo. Tais práticas não se restringiram somente ao grupo que contempla os institutos e clínicas tradicionais de formação, mas também se estenderam a locais que a priori seriam considerados como fazendo parte da formação emergente, a qual incluiria novas exigências e abordagens no atual contexto de formação. Analisando os fragmentos discursivos constata-se que não é somente porque uma diretriz orienta para um novo fazer que este se concretiza. A supervisão foi o espaço que problematizou estas questões com os alunos ao trazer as práticas desenvolvidas nos campos de estágio. Tanto no grupo representativo dos locais tradicionais de formação como nos que englobam os serviços públicos e o terceiro setor, estas práticas se atravessam, o que pode ser constatado no local 3 do grupo 1, onde se identificaram tanto práticas ditas da clínica tradicional quanto as que fariam parte da clínica ampliada. Destacaram-se atividades como observação e acompanhamento de projetos psicossociais e de oficinas socioterapêuticas, a participação nas reuniões de equipe e atendimentos individuais de crianças e adolescentes.

É interessante notar que no grupo 2, representado pelos serviços públicos, percebe-se que não necessariamente figuram práticas emergentes. As

Psicol. Argum. 2014, 32(79), Supl. 2, 45-56 
práticas relatadas transitam tanto na "formação tradicional" como na dita "formação mais abrangente". Muitas atividades são vinculadas à rede de proteção de crianças e adolescentes no município com escolas e professores, por exemplo, em visitas domiciliares, atendimentos individuais de crianças e adolescentes e suas famílias e a realização de grupos com crianças e adolescentes. Esta discussão repercutiu no campo de estágio, no qual se pôde trabalhar com o supervisor local, redimensionando o sentido do grupo e o fazer proposto pela Psicologia. Outro exemplo foi o campo que oportunizou a observação, participação e acompanhamento das oficinas pedagógicas e oficinas ocupacionais abrigadas para pessoas com deficiência junto dos oficineiros (local 6, grupo 2). No encontro acadêmico, os estudantes traziam questionamentos quanto ao atendimento individual, do grupo e familiar (local 6, grupo 2), o que acabava ficando somente no campo discursivo, não ocorrendo na prática.

Destaca-se que esta é uma questão que precisa ser desdobrada e considerada na formação, ou seja, quais limites o "campo dito da saúde pública" impõem aos psicólogos e, portanto, são estendidos aos estudantes em formação ao questionarmos os clássicos lugares de atuação. Parte-se do fato de que os diferentes níveis de atenção, a expansão das políticas setoriais vinculadas ao SUS e a inversão quanto à oferta de serviços e as ações de cuidado, agora centrado na ampliação e fortalecimento da rede e as ações de atenção básica (atenção primária à saúde/saúde mental, estratégia de saúde da família) e no crescimento de equipes multiprofissionais consolidando os serviços especializados contribuem para o fortalecimento do psicólogo no SUS (Ceccim \& Feuerwerker, 2004; Boing, 2009). Entretanto, exigem uma qualificação no processo de trabalho e no funcionamento dos serviços, assim, o psicólogo precisa se inserir tendo de dar conta da complexidade da vida, bem como das necessidades e atravessamentos que envolvem/ fazem parte do processo saúde doença, tendo que adequar às ferramentas de trabalho e o aparato teórico-técnico e da efetividade da atuação em um campo que demanda intervenções interdisciplinares por meio de equipes multiprofissionais (Dimenstein \& Macedo, 2012, p. 234-235). Alguns enunciados trazidos pelos estudantes corroboram estas questões:
Estou me sentindo mais à vontade para falar durante o grupo, meu relacionamento com os pacientes, antes um pouco distante e desencontrado, está cada vez mais próximo. (estudante EBIII - crítica às práticas).

Senti-me convocada e me defendi diante das reclamações do grupo, não conseguindo me conter, esse foi o maior desafio do EBII, ficar no lugar de observadora em um grupo que se sentia uma participante "igual" (estudante EBII - desafios na atuação/aprender fazendo).

Destaca-se uma questão que vem sendo proposta por vários estudos já citados no texto e que pôde ser vivenciada nos encontros acadêmicos: reconhecer o fato de que mesmo com tentativas de mudanças na formação acadêmica e profissional, a presença e a participação dos psicólogos nos serviços e nas equipes de saúde que compõem o SUS não necessariamente modificam ou garantem a lógica da produção de saberes e o agir diário dos profissionais. 0 espaço de supervisão acadêmica e a elaboração e posterior discussão e compartilhamento dos diários de campo são estratégias relevantes de ensino-aprendizagem, uma vez que atualizam e assumem os desafios elencados, repercutindo nos fazeres locais. No estudo em questão, percebe-se nos discursos que o psicólogo ainda aparece como mais um ator que compõe o contraditório território da Saúde Pública, e em alguns momentos também reproduz um modelo hegemônico de atuação do ponto de vista "tecnoassistencial" e ético-político. As práticas nas instituições públicas de saúde e na rede de atenção primária e de saúde mental têm sido bastante criticadas por seguirem ainda identificadas em muitos casos com uma atuação "biologizante" e "mecanizante", de caráter prescritivo, tendendo ao trabalho individualizado, ancorado em relações verticalizadas e, portanto, não focadas no usuário (Dimenstein \& Macedo, 2012).

A lógica que orienta o fazer $p s i$, o que define as técnicas e procedimentos utilizados na organização do cotidiano do trabalho e suas rotinas e, portanto, selecionam a clientela e acabam contribuindo para a diminuição da participação nos assuntos coletivos (Dimenstein \& Macedo, 2012; Yamamoto, 2007; Guareschi, Scilesk, Reis, Dhein \& Azambuja, 2010). É evidente a necessidade de uma formação que assuma em seu debate uma real estruturação 
do cuidado e dos novos modos de gestão do trabalho, ao fazerem parte do cotidiano dos serviços, sabendo que é ao mesmo tempo plano de reprodução, de experimentação e de invenção de modos de ser trabalhador (Dimenstein \& Macedo, 2012; Ferreira \& Olschowsky, 2010).

Como nos alerta Barros (2007), na prática os psicólogos têm assumido mais a função de executores de políticas e projetos exigidos em outros âmbitos e a partir de demandas exógenas à comunidade do que propriamente a função de criadores de ações a partir da análise e vivência da atividade comunitária, como ilustram os enunciados:

Um paciente estava eufórico, pelos menos é o que a equipe achava. Pensei comigo mesmo: qual é o problema de estar mais falante? Obviamente eu não sabia que ele era um paciente bipolar, mas também nem tudo é motivo para interpretar como uma manifestação da doença (estudante de EBII crítica à formação tradicional/aprender fazendo).

Essa semana eu propus uma dinâmica, a primeira delas, e mesmo ansioso na hora de explicar o que tinha que fazer, embora as coisas não tenham ocorrido como eu imaginava, soube improvisar e integrar os objetivos (estudante de EBIII - desafio à formação/aprender fazendo).

Esta situação também foi estendida aos locais cenários do terceiro setor (organizações não governamentais, entidades comunitárias e fundações), que mesmo se pensados como engajados no que constituiria a formação "mais abrangente", aparecem claramente convivendo com práticas identificadas com as da formação mais tradicional em sua descrição. Incluem desde o acompanhamento e coordenação de grupos, atendimento individual e acompanhamento das reuniões em sala de aula e com pais (oferecendo cursos e oficinas para o ensino fundamental), técnicos e a direção administrativa do centro, com as profissionais da Psicologia e Serviço Social, $\mathrm{o}$ atendimento e o acompanhamento dos monitores nos grupos com os dependentes químicos ao proporem a criação de um grupo para escuta dos mesmos.

Ao identificar estas cenas enunciativas, discutiu-se no encontro acadêmico o critério de demanda adotado para os grupos nesses locais (número de usuários ou pela indicação) e se retornou à questão da formação/práticas tradicionais, em que a
Psicologia segue no lugar de "apaga-incêndio" em certos contextos.

Torna-se relevante perceber que os projetos institucionais desenvolvidos pelos Núcleos de Práticas (clínicas, comunitárias, políticas públicas e orientação vocacional) que fazem parte do serviço-escola de Psicologia do centro em questão, na tentativa de ofertar práticas na formação "ampliada", devido às ênfases propostas pelo mesmo, nem sempre conseguem garanti-las. Isso se deve seja pelos limites identificados nos próprios espaços de atuação, seja pelo desafio em tornar efetivas de fato práticas que ainda transitam entre o tradicional e o emergente, situação que pode ser visualizada nas cenas enunciativas descritas nos diários, bem como nas discussões acadêmicas em que ficou evidente que a busca de inovação não garante ações e atividades que contemplem na sua totalidade este projeto.

De acordo com Dimenstein e Macedo (2012), há a necessidade de se aprofundar a relação ensino-serviço-comunidade para que a formação se dê em e para os serviços, bem como criar espaços coletivos em que os trabalhadores, os estudantes-estagiários e os professores-orientadores possam, em conjunto, interrogar e analisar seu cotidiano de trabalho na medida em que exercitam ações em equipe e potencializam a diversidade, bem como a interdisciplinaridade norteada pelos cuidados integrais. É justamente aqui que os diários analisados ressaltam a importância dos grupos de supervisão acadêmica, nos quais o saber e o fazer são confrontados e revisitados a todo momento. A experiência na formação ocorre em um cenário em que os profissionais, os estudantes-estagiários e os supervisores-docentes são convocados a desenvolverem práticas convergentes com as políticas públicas, em que os serviços, equipes e respectivos campos são os "espaços privilegiados de formação". A formação se constrói a partir da atuação vivencial, da atualização contínua, do aprendizado coletivo, que se aproxima da realidade investindo em habilidades e na superação das dificuldades enfrentadas no trabalho em equipe e na construção de novos pactos de convivência nos quais o envolvimento ético-político de todos os envolvidos é o centro do processo pedagógico.

Na medida em que as demandas sociais e de serviços dialogam com a universidade ensino-serviço-comunidade, exige-se uma nova concepção de ensino-aprendizagem que valorize o saber prévio dos alunos e dos técnicos, trabalhando com problemas

Psicol. Argum. 2014, 32(79), Supl. 2, 45-56 
concretos e complexos da realidade local em espaços multiprofissionais (Dimenstein \& Macedo, 2012).

A discussão e a responsabilidade destas questões se estendem para além da Psicologia ao compormos diversos saberes que constituem a Saúde ou a Assistência, tendo em vista que a Psicologia busca contribuir para os projetos políticos sociossanitários. Ao formular novos problemas e constituir a emergência de um ator político que intervém em um plano ético, provocando a análise do que está posto em funcionamento, incluem as políticas públicas, bem como os modelos assistenciais em curso e as relações interprofissionais.

No estudo apresentado, ao emergirem locais e fazeres, contrastando as categorias elencadas, algumas considerações já parecem se destacar nesta discussão. A primeira delas diz respeito ao eixo temático composto pelas cadeias intertextuais que envolvem a categoria "construção de práticas. Estas foram trazidas pelos estudantes em seus diários nesse contexto incluindo tanto características "desejáveis" e necessárias nos locais e práticas ofertadas quanto uma crítica à formação tradicional. Isso ocorre devido à atribuição de certo "engessamento" de algumas inserções em certos campos de estágio, na medida em que a proposta do EBII previa que o estudante pudesse ampliar seu foco de observação. Acontece que nem sempre os locais ofertam atividades que se adequam a esta realidade, comprovando a dificuldade, às vezes enfrentada, em compor a proposta ofertada pelo local e as expectativas do centro, como pode ser percebido nas seguintes verbalizações:

Aprendi na reunião clínica como apresentar um caso, fazer uma dialogada, como falar com o paciente (Formação tradicional - Estudante EBII)

Estou com problemas na definição do tema do meu trabalho, e em cumprir carga horária do estágio, assisto às atividades de forma pontual, não posso repeti-las e nem assistir os atendimentos, já que é só para quem faz o estágio de clínica, e a tutoria não conta como horas do estágio. Não entendo porque alguns espaços burocráticos são oferecidos como reuniões de alunos, organização de eventos, e outros não, porque tenho que circular em várias atividades e não posso acompanhar nenhuma em profundidade, me sinto meio deslocada, não vejo muito sentido nisso (Crítica às práticas - Formação tradicional - Estudante EBII)

É importante esclarecer que já houve algumas tentativas de adequação de alguns locais a esta modalidade de estágio, justamente pelo fato de a oferta já ser mais restrita aos EBs, o que só dificultava a tarefa para o estudante: pensar em investigar uma proposta em campo que não dava condições de fazê-lo, não flexibilizando sua atuação. Neste formato, as atividades oferecidas tornavam-se recortadas, sem continuidade, pontuais e sem muito sentido para os estudantes, evidenciando os limites do modelo das ênfases propostas.

De acordo com Yamamoto \& Oliveira (2010) e Barros (2007), considerar os engendramentos microssociais em suas similaridades e singularidades em relação ao cenário macroestrutural exposto, necessita-se ir além das reflexões que enfocam somente o referencial teórico-metodológico do psicólogo, associados de forma simplista à sua atuação em políticas públicas. Dependendo das conjunturas locais de gestão e operacionalização, o psicólogo tanto pode atualizar ordens socialmente excludentes quanto romper com os processos já instituídos. Somam-se ainda a presença de ambiguidades entre as pretensões dos profissionais e os desdobramentos de sua prática, sendo um entrave comum ao psicólogo a intersecção, por vezes conflitiva, entre as demandas institucionais e o campo de forças que emerge do contexto microssocial no qual se dá a prática cotidiana do psicólogo.

Faz-se notar uma relação entre categorias, que desvela ambiguidade, identificada como um ponto crítico no corpus:

Fiz acompanhamento de triagem com a psicóloga, é bom ter modelos e importantíssimo observar as intervenções. Saí mais uma vez com aquela sensação de quero mais (Formação tradicional/aprender fazendo/formação emergente - Estudante de EBII, local 3, grupo 1).

Poder estar no setting logo no início dos estágios é muito gratificante, mesmo tendo como tarefa a observação. Acompanhar o psicólogo nas triagens e após os atendimentos, participar da supervisão, onde realmente tenho aprendido muito (aprender fazendo/Formação tradicional - Estudante de EBII, local 2 grupo 1). 
Evidenciam-se assim os desafios na formação, exigindo que teoria e prática não sigam dissociadas e nem postergadas para um momento específico da mesma. Devido à exigência de novas atuações nos campos ofertados, em uma mesma atividade podem coexistir estudantes com tarefas diferentes (EBII, EBIII e EBIV), mas que se complementam em sua atuação. Os diários retratam a emergência de novos fazeres, que ao serem discutidas no espaço acadêmico, deslocam o estudante para que perceba que muitas vezes não valoriza e não tem a dimensão da potencialização do seu fazer. Revela-se então a oportunidade de compreender a necessidade de se estar aberto para lidar com o que se impõe nos campos de estágio, diante do fato de que a demanda vai se transformando ao longo dos encontros e em alguns momentos surpreende, desconstrói pré-conceitos:

Foi a primeira experiência em que vi o trabalho de um psicólogo, no EBI com as visitas era diferente, agora estou vivenciando as práticas no dia a dia (aprender fazendo/teoria e prática/formação emergente - Estudante de EBII, grupo 1).

A intervenção mobilizou ansiedades por ser tudo muito novo, mas durante a coordenação e o manejo dos trabalhos com os alunos fui ficando mais à vontade, senti que seria um trabalho desafiador, o interventor se acha exposto no grupo, mas ao mesmo tempo é um aprendizado enorme (aprender fazendo/construção das práticas/formação emergente/ Ênfase do curso/teoria e prática - Estudante de EBIV, grupo 1).

Diante dos inúmeros desafios da formação, questiona-se o que é considerada uma intervenção, sendo que nos encontros acadêmicos viu-se que muitas vezes não se tem a pretensão de "grandes feitos", impactos nos estágios e inclusive nem se tem a dimensão do que a nossa presença e as vivências podem produzir. Estudos como os de Dimenstein e Macedo (2012) e Lewgoy e Scavone (2002) indicam que, orientando-se por uma concepção crítica, reflexiva e sustentada na construção do conhecimento que problematize a realidade, com novos modelos acadêmicos e metodologias de ensino, organização dos conteúdos e cenários da aprendizagem, é possível articular teoria e prática. Contando com a participação ativa do estudante no processo de aprendizagem, ao mobilizarem mudanças e iniciativas dos serviços, tocam o psicólogo diretamente em seu fazer, exigindo que este atente para o contexto em que atua, incluindo os aspectos ambientais, históricos e sociopolíticos em questão. Envolve ainda uma compreensão aprofundada dos fenômenos envolvidos, exigindo o enfrentamento dos problemas sociais expressivos nos campos acessados, nos quais a participação na discussão e negociação com os profissionais e serviços acessados vem a auxiliar na escolha e construção das estratégias de intervenção para que sejam de fato participativas e conjuntas, descritas nos enunciados:

Fiquei tão empolgada com a experiência de promoção à saúde, que na escola em que trabalho convidei o pessoal do posto e a psicóloga para divulgarem o grupo, consegui reunir algumas pessoas e já falar sobre o assunto (aprender fazendo/ teoria e prática/emergência de novos fazeres/ ênfases propostas - Estudante de EBII, grupo 2).

Coordenei uma dinâmica e foi a primeira vez que realmente não me senti pressionado, parece que pude fazer e ver o meu jeito de fazer Psicologia. Fui psicólogo, mesmo sendo estudante (Crítica à formação tradicional/desafio/aprender fazendo - Estudante de EBII, grupo 2).

Em relação ao desafio e os limites na atuação, ao discutir a relação teoria-prática nos contextos, as diferentes inserções contribuem para reflexões sobre o fazer psicológico nestes espaços. A partir dos diários, destaca-se o espaço da supervisão acadêmica em que foi discutido o fato de que não se necessita ter uma teoria a priori de forma indissociada da prática, mas o próprio exercício de estar em um campo de estágio já promove uma integração com a teoria e exigiria um posicionamento diante da problematização de uma realidade percebida (ou uma parte dela). De alguma forma, os alunos sempre assumem estar no papel de um observador participante ao assumir um posicionamento:

É impossível me considerar um observador fora do contexto, quando saio do posto sou um sujeito implicado, as cobranças para eu pense e atue como terapeuta desse grupo são provas disso. Sinto como se fôssemos adivinhar o que deve ou não ser abordado no grupo, às vezes contrariamos nosso jeito de pensar porque tem que ser do jeito

Psicol. Argum. 2014, 32(79), Supl. 2, 45-56 
da supervisão local. Nem falamos certas coisas, porque contraria o jeito de pensar (Crítica à formação - Estudante de EBIII, grupo 2)

No estágio de EBII não sou apenas um observador, existe uma cobrança para que o meu estar no grupo seja o de terapeuta, analise, interprete, consiga devolver e elaborar. Embora goste de estar nessa posição, ser reconhecido como tal, sinto que a minha função não é propriamente essa (Crítica à formação tradicional/aprender fazendo/desafio na atuação/emergência de novos fazeres /teoria e prática - Estudante de EBII, grupo 3)

A formação em Psicologia vem sofrendo mudanças em torno do currículo mínimo dos cursos de graduação, o que inclui as metodologias de ensino-aprendizagem e as experiências de estágio, ressaltando-se a necessidade da construção de novas formas de ensinar e aprender perante as mudanças contemporâneas (Mitre, et al., 2008). Autores de outras áreas de formação como Lewgoy e Scavone (2002) também têm refletido sobre as mudanças nos projetos pedagógicos dos cursos de formação de forma ampliada, a fim de unir o que é apreendido em sala de aula às vivências no cotidiano de trabalho em saúde. Enfatizam o respaldo nos projetos pedagógicos dos cursos de graduação, a fim de darem condições aos alunos de aprender a lidar com divergências, considerando que as verdades são relativas e formadas por saberes variados (Mendes, Fonseca, Brasil \& Dalbello-Araújo, 2012).

Discute-se que o deslocamento do psicólogo dos espaços tradicionais para os de convivência comunitária não se justifica pela extensão do serviço psicológico a parcelas socioeconomicamente mais desfavorecidas da população, mas pelo fato de que as comunidades possuem uma gama de redes interativas que perpassam a complexa construção de pessoas e grupos que ali vivem, podendo, assim, impulsionar a ampliação das práticas psicológicas, o que nem sempre ocorre conforme o previsto, diante da complexidade constatada neste estudo. Acrescentase que a partir das vivências dos EBs, alternativas são ofertadas a uma formação considerada tradicional, o que não exclui a necessária e oportuna discussão sobre seus limites e possibilidades como prática educativa.

\section{Considerações Finais}

Vários autores (Dimenstein e Macedo, 2012; Yamamoto \& Oliveira, 2010, Barros, 2007; Yamamoto, 2007; Guareschi et al., 2010; Scardelli \& Junqueira, 2011; Ferreira \& Olschowsky, 2010) vêm sinalizando e alertando a necessidade de se repensar as formas de atuação do psicólogo, remetendo não só a formação acadêmica destes profissionais, mas também as ferramentas que a Psicologia vem dispondo para o desenvolvimento de seu trabalho. Não é novidade que a Psicologia vem enfrentando limitações quanto à atuação e as práticas desenvolvidas, tanto em serviços técnico-especializados, estabelecimentos ou programas de cuidado à saúde e proteção de direitos quanto nas demais atividades gerenciais e de regulação dessas políticas.

As dificuldades e contradições apontadas aqui vão além de uma crítica à atuação ainda em um modelo clínico individual, estendendo-se ao desafio que tem sido inserir-se em um projeto político proposto pelas políticas sociossanitárias vigentes. Estas envolvem desde o rompimento com uma lógica assistencial até a ampliação de seus princípios para o acesso e a compreensão do que se considera cuidado. Soma-se a isso o alerta de que os profissionais ainda precisam avançar nas intervenções nos serviços (de saúde, assistência, entre outros) para além do ensino tecnicista, independentemente dos locais de atuação, sejam vistos como "mais tradicionais" ou "mais abrangentes", incluindo a população atendida e as necessidades e demandas geradas (Bernardes, 2010). Nesses 50 anos de história da profissão no Brasil, continuam os questionamentos do que isso vem representando em termos de práticas ofertadas para a inserção dos estudantes em formação na área.

0 desafio reificado é consolidar a Psicologia enquanto profissão comprometida com a sociedade (Campos, 1994). Neste estudo, encontra-se dificuldades similares a aquelas já apontadas em outros estudos (Yamamoto, 2007; Macedo \& Dimenstein, 2009; Dimenstein \& Macedo, 2012). Os campos acessados e acompanhados na pesquisa têm se mostrado uma conjuntura fértil e privilegiada de atuação, na qual os princípios e diretrizes propostos de forma macropolítica (através das DNC e políticas sociais, por exemplo) têm convocado e provocado os profissionais para que revejam e reflitam sobre as suas ações (em saúde, na assistência, na gestão e 
no terceiro setor). Este fator acaba se refletindo na formação, em que o saber-fazer, ao ser problematizado pelos estudantes em suas vivências de estágio, desafia a todos (campo de estágio, supervisão local, estudante e supervisão acadêmica) para a proposição de soluções criativas no cotidiano desses campos diante das exigência das habilidades e competências postas em discussão.

A partir da experiência da supervisão acadêmica desta modalidade relativamente nova na formação que são os EBs, percebe-se que muitos profissionais vêm abrindo campos de atuação, bem como vêm sendo desacomodados nestes espaços já não tão "confortáveis" nem tão "previsíveis". Impulsionados pela presença de estudantes em campos de estágio que vêm questionando os fazeres e não fazeres e auxiliando no desenvolvimento de experiências transformadoras e inovadoras, impõe-se a (des) construção de (novas) competências e habilidades psicossociais. A provocação segue mediante compromissos ético-políticos que precisam ser reassumidos de forma corajosa e tolerante diante de um fazer incerto e complexo que segue em transformação (Dimenstein \& Macedo, 2012).

Para haver a transformação dos sujeitos, são necessárias experiências cotidianas de trabalho que promovam a gestão de processos de mudanças de si e dos entornos, direcionadas para a construção de saberes e práticas e do poder de autoria de modo coletivo e produtor de subjetivação. No contexto da Pedagogia da Implicação, dar-se-iam processos coletivos de autoanálise e autogestão e capacidade criativa ativa de intervenção nas situações vivenciadas pelos participantes, dirigida e produzida por coletivos de trabalho (Fagundes, 2006; Lima \& Santos, 2012).

Em suma, finaliza-se com a reflexão de Dimenstein e Macedo (2012), destacando que ao se inserirem nos novos espaços, tanto os profissionais quanto os estudantes contribuem na problematização do cotidiano e na forma como articulam/operam seus campos de saberes e práticas. 0 lugar que ocupam tem implicações diretas na maneira como atuam, produzindo interferências naquilo que já está posto frente às demandas sociais acessadas $\mathrm{e}$ exigidas. Mesmo percebendo-se impotentes em certos momentos perante um cenário que lhes convoque para um tipo de atuação mais coletiva, política e problematizadora das condições sociais produzidas nesses espaços, não é mais possível esconder-se enquanto profissionais protegidos em seu saber técnico diante dos desafios do campo das políticas sociais, no qual parece que só nos resta uma alternativa: o "aprender fazendo".

\section{Referências}

Associação Brasileira de Ensino e Pesquisa. (2009) Construção de Acordos sobre a Aplicação das Diretrizes curriculares para os Cursos de Psicologia no país. Brasília. Recuperado em 6 de maio de 2011, de http://www.abepsi.org.br/web/diretrizes.aspx.

Barros, J. P. P. (2007). Psicologia e políticas públicas: um estudo sobre a práxis do(a) psicólogo(a) no projeto Raízes de Cidadania e nos Centros de Referência da Assistência Social (CRAS) de Fortaleza. Monografia de Conclusão de Curso, Departamento de Psicologia, Universidade Federal do Ceará, Fortaleza.

Bernardes, A. G. (2010). Psicologia e o Sistema Indivíduo de Saúde. In N, M. F. Guareschi, A. Scisleski, C. Reis, G. Dhein \& M. A. Azambuja (Orgs.). Psicologia, Formação, Políticas e Produção em Saúde (pp. 206220). Porto alegre: EDIPUCRS.

Bernardes, J. (2006). Formação generalista em psicologia e sistema único de saúde. In Fórum Nacional de Psicologia e Saúde Pública: contribuições técnicas e políticas para avançar o SUS. Brasília Distrito Federal: Conselho Federal de Psicologia.

Bernardes, J. (2010). A Psicologia no SUS 2006: alguns desafios na formação. In: M. J. P. Spink (Org.) A psicologia em diálogo com o SUS: prática profissional e produção acadêmica (pp. 105-127). São Paulo: Casa do Psicólogo.

Bernardes, J. (2012). A Formação em Psicologia após 50 anos do primeiro Currículo Nacional da Psicologia alguns desafios atuais. Psicologia: Ciência e Profissão, 32(Esp.), 216-231.

Boing (2009). O psicólogo na atenção básica: uma incursão pelas políticas públicas de saúde brasileiras. Dissertação de Mestrado. Programa de Pós-Graduação em Psicologia, Universidade Federal de Santa Catarina, Florianópolis.

Campos, G. W. S. (1994). Considerações sobre a arte e a ciência da mudança: revolução das coisas e reforma das pessoas. o caso da saúde. In. L. Cecílio (Org.). Inventando a mudança na saúde (pp. 29-88). São Paulo: Hucitec.

Psicol. Argum. 2014, 32(79), Supl. 2, 45-56 
Ceccim, R. B. \& Feuerwerker, L. C. (2004). Mudança na graduação das profissões de saúde sob o eixo da integralidade. Cadernos de Saúde Pública, 20(5), 1400-1410.

Conselho Federal de Psicologia (2006). I Fórum Nacional de Psicologia e Saúde Pública: contribuições técnicas e políticas para avançar o SUS. Brasília, DF: Conselho Federal de Psicologia.

Dimenstein, M. \& Macedo, J. P. (2012). Formação em Psicologia: requisitos para atuação na Atenção Primária e Psicossocial. Psicologia: Ciência e Profissão, 32(Esp.), 232-245.

Fagundes S. (2006). Águas da pedagogia da implicação. Intercessões da educação para a política pública de saúde. Tese de Doutorado, Universidade Federal do Rio Grande do Sul, Programa de Pós-Graduação em Educação, Porto Alegre.

Fairclough, N. (2001). Discurso e mudança social. Brasília: UnB.

Ferreira, S. R., \& Olschowsky, A. (2010). Residências: uma modalidade de ensino. In A. P. Fajardo, C. M. F. Rocha, \& V. L. Pasini (Orgs.). Residências em Saúde. Fazeres e saberes na formação em Saúde. Porto Alegre: Hospital Nossa Senhora da Conceição.

Guareschi, N. M. F., Scisleski, A., Reis, C., Dhein, G., \& Azambuja, M. A. (Orgs.) (2010). Psicologia, formação, politicas e produção em saúde. Porto Alegre: EDIPUCRS.

Iñiguez, L. (2005). Análisis del Discurso. Barcelona: UOC, 2005.

Lewgoy, A. M. B. \& Scavone, M. L. A. (2002). Supervisão em Serviço Social: a formação do olhar ampliado. Revista Virtual Textos \& Contextos, 1, 55-65.

Lima M. \& Santos, L. (2012). Formação de Psicólogos em Residência Multiprofissional: transdisciplinaridade, núcleo profissional e saúde mental. Psicologia: Ciência e Profissão, 32(1), 126-141.
Macedo, J. P. \& Dimenstein, M. (2009). Psicologia e a produção do cuidado no campo do bem-estar social. Psicologia \& Sociedade; 21(3), 293-300.

Maingueneau, D. (2010). Crítica (Análise) - As condições de uma análise crítica do discurso. In S. Possenti \& M. C. P. S. Silva (Org.). Doze conceitos em Análise do Discurso (R. L. Baronas, trad., pp 63-78). São Paulo: Parábola.

Mendes, F. M. S.; Fonseca, K. A.; Brasil J. A., \& DalbelloAraújo, M. (2012). Ver-Sus: relatos de vivências na formação de Psicologia. Psicologia: Ciência $e$ Profissão, 32(1), 174-187.

Mitre, S. M.; Siqueira-Batista, R.; Girardi-de-Mendonça, J. M; Morais-Pinto, N. M.; Meirelles, C. A. B.; Pinto-Porto, C. et al. (2008). Metodologias ativas de ensino-aprendizagem na formação profissional em saúde: debates atuais. Ciência \& Saúde Coletiva, 13(2), 2133-2144.

Queiroz, D. T., Vall, J., Souza, A. M. A., \& Vieira, N. F. C. (2007). Observação participante na pesquisa qualitativa: conceitos e aplicações na área da Saúde. Revista da Enfermagem UERJ, 15(2), 276-283.

Ribeiro, S. \& Luizio, C. (2008). As Diretrizes Curriculares e a formação do psicólogo para a saúde mental. Psicologia em Revista, 14(2), 203-220.

Scardelli, I. R. \& Junqueira, V. (2011). o SUS como desafio para a formação em Psicologia. Psicologia: Ciência e Profissão, 31(2) 340-357.

Yamamoto, O. H. \& Oliveira, I. F. (2010). Política Social e Psicologia: uma trajetória de 25 anos. Universidade Federal do Rio Grande do Norte. Psicologia: Teoria e Pesquisa, 26(Esp.), 9-24.

Yamamoto, O. H. (2003). Questão Social e políticas públicas: revendo o compromisso da Psicologia. In A. M .B. Bock (Org.). Psicologia e compromisso social. (pp. 3754). São Paulo: Cortez.

Yamamoto, O. H. (2007). Políticas sociais, terceiro setor e compromisso social: perspectivas e limites do trabalho do psicólogo. Psicologia \& Sociedade, 19(1), 30-37. 